\title{
The use of a new design irrigator for the emergency treatment of chemical eye injuries in an accident and emergency department
}

\author{
M. T. WATTS \& A. MULIRA \\ Department of Ophthalmology, The Alexandra Hospital, Redditch, \\ England
}

\section{SUMMARY}

The introduction of a hand-held drench hose into a district general hospital accident and emergency department, for the emergency irrigation of chemically injured eyes is reported. The hose is described, together with the technique of irrigation. The advantages that a high-flow, low pressure system affords over conventional irrigation methods are discussed.

The system appears to offer a simple, immediately available, effective tool for emergency eye care, which is suitable for use by a variety of personnel.

\section{INTRODUCTION}

Chemical injury to the eye is a common emergency which presents to specialist eye units and general accident and emergency departments alike. The rapid assessment and management of these injuries is vital to the survival of an eye, and measures undertaken immediately determine the ultimate prognosis more than do any subsequent more radical procedures (Dohlman \& Pfister, 1972). Early irrigation is essential (Eagling \& Roper-Hall, 1987), with as rapid dilution of a noxious agent as possible. Conventional techniques of irrigation, however, provide relatively slow rates of flow of the diluent, since excessive pressure can be damaging to the eye. Most irrigating systems are developments of an intravenous giving set directed at the eye (Tan, 1970). It has been suggested that irrigation must be continued for $30 \mathrm{~min}$ with the time-honoured undine, before adequate dilution is achieved for alkali burns (Ralph, 1985).

Correspondence: M. T. Watts, Senior Registrar in Ophthalmology, The Royal Hallamshire Hospital, Sheffield, England. 
This paper describes experience in the introduction of an adaptation of industrial $\stackrel{5}{3}$ equipment into a district general hospital accident and emergency.department for eye $\stackrel{\oplus}{\varrho}$ irrigation.

\section{MATERIALS AND METHODS}

The conventional undine and intravenous giving set provide a flow of saline of $0 \cdot 2$ and $\stackrel{\varnothing}{\circ}$ $0.41 / \mathrm{min}$ respectively. This relatively low flow rate ensures a low pressure stream of $\mathscr{\omega}$ water. Any attempt to increase the flow through the narrow bore of the pipe would $\vec{\circ}$ result in excessive pressure, as well as rapid depletion of the supply of water, $\overrightarrow{\vec{H}}$ particularly with the undine. The requirement for optimal rapid dilution is a high flow at a low pressure. This can be achieved by aeration of the stream. By introducing an 'air $\stackrel{\oplus}{3}$. gap' into the stream, which sucks in air to cause the water to froth, the pressure is reduced. Such devices have not previously been used in a hospital environment, but? have been available on the factory floor for some years, in the form of a hand-held hose $\overrightarrow{0}$ which delivers an aerated flow of water.

Such a hose was installed at the Alexandra District General Hospital, Redditch. It incorporates three fine stainless steel meshes to filter out fine particulate matter from the mains fed water supply, as well as a limiting valve to restrict maximum flow. The ${ }^{\Phi}$ device, illustrated in Figure 1, is hand held, and has a constantly variable trigger, to $\vec{\infty}$ regulate the flow between zero and the maximum delivery of $10 \mathrm{l} / \mathrm{min}$.

Although it is unusual to acquire an ocular infection from mains water, a number specimens of water were cultured on blood agar plates in order to be sure of its safet $\%$

Sixty patients who had suffered a chemical injury to the eye were treated over a 5month period. They were all first examined to exclude a perforating injury or tear of the $\frac{\Phi}{\circ}$ conjunctiva, and, if necessary, topical anaesthesia administered (G.amethocaine $1 \cdot 0 \%$ ). $\overrightarrow{\overrightarrow{0}}$ Irrigation was then undertaken using the drench hose, with the patient supine, and head $\exists$ tilted back over a hand-basin to allow drainage of the water. Both lids were everted, any particulate matter removed, and irrigation continued until all visible contaminants had been removed. Alkali-burned eyes were irrigated for at least $10 \mathrm{~min}$.

The eye was then examined again at the slit lamp, and fluorescein stain applied to detect any epithelial loss. Patients with epithelial defects were given chloramphenicol ointment and an eye pad applied for $24 \mathrm{~h}$. All were given prophylactic Guttae. chloramphenicol drops to take four times a day for five days. They were reviewed at between one and four days, and in particular, the presence of any clinical infection looked for.

\section{RESULTS}

Sixty patients who had suffered chemical injury were treated over a 5 -month period. In all, the hose was effective in producing rapid dilution of the agent. A number of patients $\stackrel{?}{?}$ complained that the water was uncomfortably cold; others found it soothing. No 


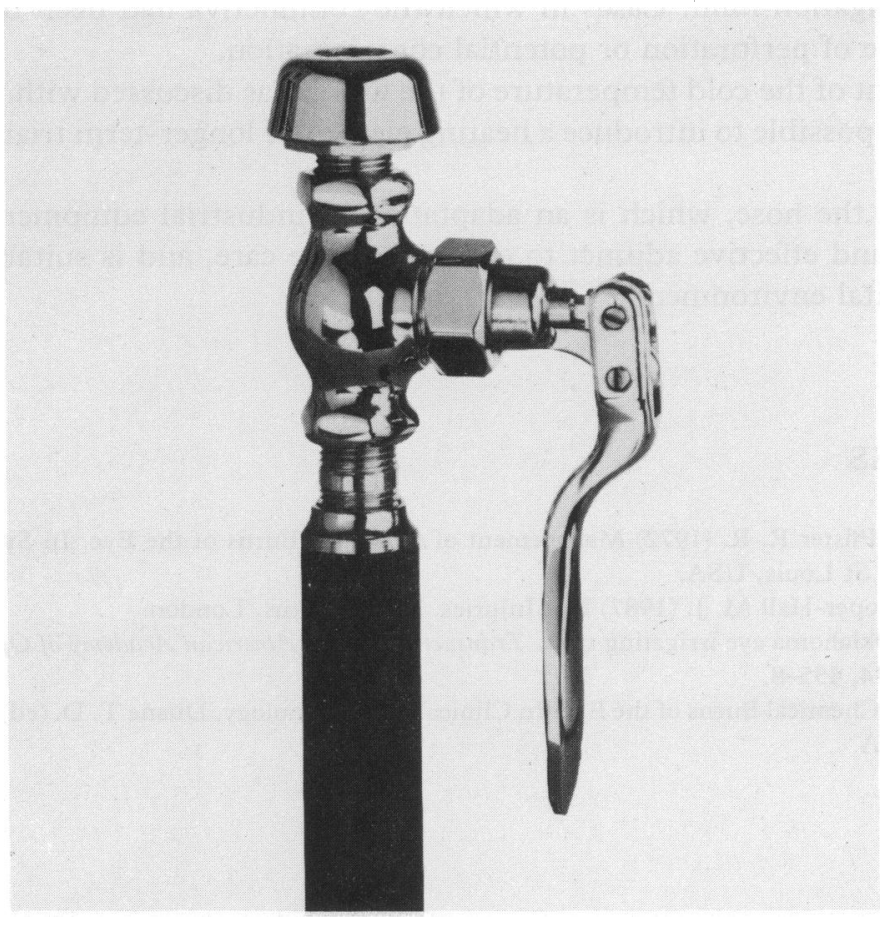

Fig. 1 SE-921 Counter top/aerated drench hose (1989).

incidence of clinically significant infection was detected, all patients having been given prophylactic antibiotics. In several patients it was not possible to remove all particulate matter with the hose alone, but this was achieved with a cotton bud. Flowing smoothly and intimately across and around the contours of the eye, aerated water in fact tends to be more effective at picking up fine particles than a steady stream which tends to hit and splash away.

\section{DISCUSSION}

The hose as adapted to hospital conditions appears to offer a simple, effective method of irrigation of eyes. It has the advantage over conventional techniques of being simple to use, immediately ready for use, and also, in not requiring repeated supplies of disposable equipment, providing a cost saving in the long term.

The fact that the water is not sterile, even though filtered, does not appear to have introduced any problems from sepsis. In the presence of antibiotic prophylaxis, which tends to be given anyway following irrigation, there does not appear to be a necessity to 
use a sterile irrigation fluid. Cases in which the conjunctiva had been breached were $\bar{\sigma}_{\bar{\Phi}}^{\mathrm{m}}$ excluded in case of perforation or potential contamination.

The complaint of the cold temperature of the water was discussed with the suppliers, 3 and it would be possible to introduce a heating element if longer-term trials showed it to? be appropriate.

In summary, the hose, which is an adaptation of industrial equipment, appears to provide a safe and effective adjunct to emergency eye care, and is suitable for a wide variety of hospital environments.

\section{REFERENCES}

Dohlman C. H. \& Pfister R. R. (1972) Management of Chemical Burns of the Eye. In Symposium on the Cornea. Mosby, St Louis, USA.

Eagling E. M. \& Roper-Hall M. J. (1987) Eye Injuries. Butterworths, London.

Tan B. G. (1970) Oklahoma eye irrigating tube. Transactions of the American Academy of Ophthalmology and $\overrightarrow{+}$ Ralph R. A. (1985) Chemical Burns of the Eye. In Clinical Ophthalmology. Duane T. D. (ed), Harper \& Row을 Phildelphia, USA. 